\title{
Políticas turísticas, actores sociales y ecoturismo en la península de Yucatán
}

\section{Tourism polices, social partners and ecotourism in the Yucatan peninsula}

\author{
Maria Raimunda Araújo-Santana * \\ Manuel Roberto Parra-Vázquez* \\ Ernesto Benito Salvatierra-Izaba * \\ Ana Minerva Arce-Ibarra* \\ Florencia Montagnini**
}

\begin{abstract}
In order to indicate who is involved and their contribution to ecotourism in the Yucatan Peninsula, Mexico, this study examines tourism polices and social partners as factors that impel the development of ecotourism in the Mayan area. To that end, interviews were held with representatives from government agencies, non-governmental organizations, community organizations and touristic operators. The results showed that various government and no-government programs support ecotourism projects. The distribution of this support is uneven across community and relationship among actors is insufficient, resulting in short-term projects that only partially cover the objectives of ecotourism.
\end{abstract}

Keywords: ecotourism, sustainable development, tourism policies, social actors, strategies.

\section{Resumen}

En este documento se analizan las políticas turísticas y los actores sociales como factores que impulsan el ecoturismo en la zona maya de la península de Yucatán. Se entrevistaron a representantes de dependencias gubernamentales, organizaciones no gubernamentales, comunitarias y operadoras turísticas. Los resultados confirman que los programas gubernamentales y no gubernamentales apoyan proyectos ecoturísticos, sin embargo, la distribución de los apoyos es desigual entre las comunidades y la cooperación entre los actores es insuficiente, lo que resulta en proyectos a corto plazo que cubren parcialmente los objetivos del ecoturismo y del desarrollo sustentable.

Palabras clave: ecoturismo, desarrollo sustentable, política turística, actores sociales, estrategias.

* El Colegio de la Frontera Sur, México. Correos-e: maraujo@ecosur.mx y raybr23@hotmail. com; mparra@ecosur.mx, bsalvati@ecosur.mx, aarce@ecosur.mx

** Yale University, School of Forestry and Environmental Studies, New Haven, USA. Correo-e: florencia.montagnini@yale.edu 


\section{Introducción}

En los países en vías de desarrollo, el ecoturismo es considerado como una estrategia económica que contribuye a la conservación y la generación de ingresos para las comunidades rurales (Drumm y Moore, 2002). Ante el fracaso del turismo convencional, esta nueva modalidad de turismo surgió dentro del discurso del desarrollo sustentable, como un instrumento de gestión de los recursos para satisfacer las necesidades socioeconómicas, ambientales y estéticas, respetando la integridad cultural e involucrando numerosas actividades, así como a actores sociales en los procesos de gestión (Ceballos, 1998). El término ecoturismo se ha definido de diferentes maneras, pero para efectos de este análisis se toma el siguiente concepto que la Sociedad Internacional de Ecoturismo ha emitido: "el viaje responsable a zonas naturales que conserva el medio ambiente y mejora el bienestar de las poblaciones locales" (The Ecotourism Society, 1993). En México, a partir de los ańos ochenta, el ecoturismo ha sido utilizado como una estrategia de conservación y de reducción de la pobreza (BID, 2008; Sectur, 2007). Desde entonces, diversas instancias gubernamentales y organizaciones no gubernamentales (ONG) han incrementado el apoyo para el desarrollo de proyectos ecoturísticos en comunidades rurales (Brown, 1999; Daltabuit et al., 2000).

La península de Yucatán es una región biogeografía situada al noreste de Centroamérica, y en México, incluye los estados de Quintana Roo, Yucatán y Campeche. En esta región existe una compleja relación entre las actividades pesqueras y turísticas, siendo estas últimas, las que, en su mayoría, han resuelto los problemas de desarrollo regional en Yucatán, particularmente, en Quintana Roo; dicho estado es rico en atractivos naturales y culturales, cuenta con una superficie de $51,000 \mathrm{~km}^{2}$ e incluye una parte importante de la zona maya. Sus actividades productivas se basan en la agricultura, ganadería, apicultura, pesca, explotación forestal y turismo; sin embargo, el uso inadecuado de los recursos naturales, el crecimiento demográfico y los bajos precios de mercado han provocado que los beneficios económicos de estas actividades sean cada vez menos redituables (Carballo, 2002; Daltabuit et al., 2000). Por lo anterior, los grupos interesados en incursionar en el ecoturismo buscan mejorar sus ingresos y conservar sus recursos naturales a través de distintas estrategias, que para fines de este estudio, son consideradas como los planes y programas de acción que instrumentan los actores sociales para asegurar el logro de sus objetivos.

El propósito de este artículo es analizar las políticas turísticas y los actores sociales como factores que impulsan el ecoturismo en la zona maya de Quintana Roo. La hipótesis que se plantea es que el desarrollo del eco- 
turismo está determinado por las políticas turísticas, mientras que el interés de los grupos organizados, por la conservación de los recursos naturales.

Esta investigación forma parte de una amplia investigación cuyo objetivo general es analizar la contribución del ecoturismo en los modos de vida de las comunidades rurales de la península de Yucatán.

\section{Políticas turísticas y ecoturismo}

\subsection{Políticas turísticas}

Las políticas turísticas se originan de las políticas económicas, las cuales se constituyen de diversas áreas de actuación y se establecen entre las políticas macro y microeconómicas. En el marco de la política económica, el proceso de decisión combina las políticas instrumentales con las políticas sectoriales, y estas últimas, atienden a una parcela concreta de actividad económica, siendo aquí donde se enmarca la política turística. Por lo tanto, al derivarse de la política económica general, la política turística mantiene elementos comunes con ésta y persigue actuar o incidir en un ámbito concreto de la esfera productiva de una economía (Monfort, 2000), en este contexto, las políticas turísticas son "un conjunto de actitudes y estrategias que una colectividad organizada adopta ante el fenómeno turístico". Asimismo, estas políticas permiten una reflexión sobre la conformación de los compromisos políticos para una recomposición social (Castillo y Vargas, 2007). Los objetivos de la política turística, según Monfort (2000), son divergentes para cada zona, región o país; además, dependerán de los productos turísticos existentes y de las motivaciones y directrices de las autoridades responsables de institucionalizar dicha política turística.

\subsection{Ecoturismo}

El ecoturismo surgió en la década de los ochenta como resultado de la aceptación mundial a favor de prácticas productivas más sustentables y con menor impacto al medio ambiente (Boo, 1990). Este concepto cobró importancia a partir de 1987 en el marco del Informe Bruntland, donde se establecieron los elementos básicos del desarrollo sustentable. El ecoturismo constituye una herramienta importante para el desarrollo social y económico y debe ser implementado, respetando los principios y lineamientos para el involucramiento activo y apropiado de carácter intersectorial, en el que participen autoridades públicas, comunidades locales, administradores de parques y Áreas Naturales Protegidas (ANP), las ONG y empresas privadas (Drumm y Moore, 2002). A nivel mundial, los pro- 
gramas y destinos ecoturísticos, se multiplican en las áreas naturales; sin embargo, el turismo no planificado o, planificado y ejecutado de manera deficiente, erróneamente denominado ecoturismo, puede producir impactos negativos graves para el medio ambiente y para las comunidades, anulando los beneficios por los que fue concebido (Rome, 1999).

Para que la práctica del ecoturismo sea exitosa es fundamental que circunscriba la formación de una conciencia ambiental y el interés compartido entre todos los actores involucrados en la actividad. En este sentido, los proyectos ecoturísticos deben reunir y cumplir con seis principios básicos: 1) que sea de bajo impacto sobre los recursos naturales de las áreas protegidas; 2 ) involucrar a los actores (individuales, comunidades locales, operadores turísticos, las ONG e instituciones gubernamentales) en las fases de planificación, desarrollo, implementación y monitoreo; 3) generar ingresos equitativos para las comunidades, actores participantes y operadoras turísticas; 4) respetar las culturas y tradiciones locales; 5) generar ingresos para la conservación de las áreas protegidas y, 6) concientizar a todos los actores involucrados acerca de su papel en la conservación (Ceballos, 1998; Drumm y Moore, 2002).

Para entender las dinámicas del ecoturismo, Ashley (2000) señala que existen diferentes perspectivas, entre ellas, la que se refiere al enfoque económico, comercial, ambiental, así como la que se enfoca en el desarrollo social, la cual aborda la participación de los actores sociales como un componente importante para maximizar los beneficios sociales, económicos y ambientales del ecoturismo. La principal limitante para el estudio del ecoturismo en la zona de estudio es la falta de investigación acerca de los actores que deciden sobre el funcionamiento y la realidad de los proyectos ecoturísticos. Por ello, es importante conocer los procesos de las políticas turísticas, sus repercusiones, los actores y las estrategias que utilizan para llevar a cabo proyectos ecoturísticos en la zona de estudio.

\section{Conformación del territorio de Quintana Roo}

La conformación de lo que hoy conocemos como el territorio de Quintana Roo se remonta a la primera mitad del siglo XIx y se vincula con la actuación de diversos grupos sociales a lo largo de procesos históricos como la conquista y la guerra de castas, los procesos de colonización de los años treinta a través de políticas agrarias, la explotación de recursos forestales en la parte sur por los habitantes de Belice, y la revolución cubana, que fue un elemento clave para la constitución del territorio de Quintana Roo. En los sesenta la economía del territorio de Quintana Roo se basaba en la explotación de maderas finas y de chicle; sus casi inexis- 
tentes vías de comunicación y medios de transporte mantenían a la entidad aislada del resto del país y con una estructura económica en crisis, derivada del agotamiento del enclave forestal (Dachary, 1992).

La revolución cubana tuvo un impacto importante en términos económicos y sociopolíticos en el Estado debido a que orilló al mercado turístico norteamericano a la búsqueda de nuevos enclaves turísticos, lo que significó una oportunidad para México de establecer nuevos polos de desarrollo turístico en el Caribe. En este periodo, sucedieron varios acontecimientos importantes en el estado, entre ellos, la elaboración del Plan Maestro de Cancún, en 1972, realizada por el Fondo Nacional de Fomento al Turismo (Fonatur) y financiado con créditos del Banco Mundial (вм) y del Banco Interamericano de Desarrollo (BID). En 1974 se promovió el diseño de un Plan de Desarrollo del Territorio Quintana Roo y se emprendieron un conjunto de políticas orientadas al desarrollo y el repoblamiento del territorio a través de programas agroindustriales, agrícolas, pesqueros, ganaderos y turísticos con la creación del polo de desarrollo llamado Cancún. El advenimiento de estas acciones llevó a una subdivisión de las regiones en cuanto al tipo de producción y formas de explotación de los recursos predominantes de cada región. En resumen, estas políticas, basadas en esquemas de modernización, incidieron en las formas de ocupación territorial de la entidad. La actual estructura del estado muestra una clara diferenciación en función de la economía y sus diferentes sectores: primario, secundario y terciario, este último representado principalmente por el turismo.

\subsection{Polos de desarrollo turístico}

En los años setenta, el cambio de rumbo en el modelo económico llevó al gobierno federal a impulsar políticas de planeación nacional, basadas en Centros Integralmente Planificados (CIP). El término polos de desarrollo tiene antecedentes en la teoría de crecimiento y fue utilizado por Perroux en los ańos cincuenta para explicar cómo se produce el crecimiento económico y las razones por las que todo proceso de crecimiento tiende a ser desequilibrado.

En México, el objetivo de la política turística se ha enfocado en incrementar los ingresos nacionales, disminuir la salida de divisas y redistribuir la riqueza. En particular, se ha buscado propagar un efecto multiplicador para generar empleos, el aumento de los ingresos y el estímulo de otros sectores económicos marginales para alcanzar un mejoramiento en las condiciones de vida de la población marginada (Castillo y Vargas, 2007).

En el caso del proyecto Cancún, desde su plan maestro antes mencionado, se contempló la creación de una ciudad para una población de 
200,000 habitantes, infraestructura en comunicaciones y transportes que incluían un aeropuerto internacional y facilidades de lotes para inversión en equipamiento hotelero. En 1974, el territorio de Quintana Roo se convirtió formalmente en estado de la federación y, posteriormente, se inauguró el aeropuerto internacional, acción que suscitó que los primeros hoteles iniciaran sus actividades turísticas. En 1975, Cancún se había consolidado como destino turístico con 18,000 habitantes, flujo migratorio estable, más de 5,000 empleos, 1,500 cuartos y más de 100,000 visitantes en la temporada de invierno 1976-1977 (Castillo y Vargas, 2007).

En 1980, el gobierno aprobó la Ley Federal de Turismo en la que se contemplaron las zonas de desarrollo turístico como estrategia de diversificación de la oferta dirigida al mercado interno, intentando integrar a los campesinos al sector a través de fideicomisos, proporcionándoles oportunidades para instaurar negocios afines al turismo (Pérez y Carrascal, 2000). En esta década se publicó el Programa Nacional de Desarrollo con lineamientos específicos que creaban las condiciones para el establecimiento de las políticas sectoriales, hechos que coincidieron con el periodo de disminución de la actividad turística ocasionada por el bajo flujo del turismo extranjero debido a la crisis petrolera.

La política de ajuste estructural enmarcada en el modelo neoliberal y, puesta en marcha en 1982 por José López Portillo, se caracterizó por la apertura comercial y la inclusión del país en el Tratado de Libre Comercio de América del Norte (TLCAN), y que persiste a la fecha. Dentro del modelo neoliberal, durante la administración federal de Miguel de la Madrid (1982-1988) se intentó convertir al país, de un régimen totalmente paternalista a un esquema de renovación en los ámbitos sociales y productivos, entre ellos el sector turístico; bajo este nuevo paradigma, la situación se volvió compleja para la política turística ya que implicó reconocer elementos de disolución del Estado moderno actual y la ampliación de la brecha entre los que tienen los medios y los que no los tienen, patentizado en el desarrollo tecnológico y el subdesarrollo social como las políticas que modernizan (Castillo y Vargas, 2007).

En 1988, en el marco del modelo de desarrollo sustentable, el Gobierno Federal e instituciones internacionales, así como la iniciativa privada, implementaron el рмм (Programa Mundo Maya), cuyo punto de partida fue el fortalecimiento de la región (Daltabuit et al., 2000) a través de estrategias y acciones orientadas al desarrollo de nuevos productos y la consolidación de la oferta existente en el marco del desarrollo turístico sustentable, con la participación de los sectores público y privado, incorporando a las comunidades locales. En los años noventa, bajo el auspicio del Tratado Trilateral del Libre Comercio, el gobierno impulsó las siguientes estrategias: la conservación productiva de los recursos naturales, sobre 
todo de las ANP, y la creación de dependencias gubernamentales y organismos no gubernamentales conservacionistas con programas específicos para el desarrollo de corredores, rutas y empresas ecoturísticas (Castillo y Vargas, 2007).

En el año 2000 el ecoturismo fue reconocido como un sector económico prioritario y, por ello, el Gobierno Federal estableció la Política y Estrategia Nacional para el Desarrollo Turístico Sustentable con el propósito de garantizar, a futuro, el desarrollo sustentable del sector, mediante la participación directa de los pobladores locales, siendo ellos los principales beneficiarios (Sectur, 2002).

En el sexenio de Vicente Fox Quezada, en el marco del Programa Nacional de Turismo, se firmó el Convenio General de Colaboración para impulsar la elaboración del Plan Estratégico de Turismo de Naturaleza 2006-2015. A partir de este convenio, se han adoptado diferentes instrumentos para su ejecución como la publicación de guías para el desarrollo de proyectos de ecoturismo y la formulación de algunos instrumentos de políticas sectoriales que actualmente constituyen la base para el diseño de una política nacional para el desarrollo sustentable del turismo de naturaleza; a su vez, la política turística de la administración de Felipe Calderón Hinojosa (2006-2012) continuó con el planteamiento del sexenio anterior.

\subsection{Repercusiones de las políticas de desarrollo en el territorio de Quintana Roo}

Los efectos de las políticas turísticas en Quintana Roo se pueden apreciar de dos formas: a) por un elevado desarrollo económico a partir del complejo turístico de Cancún y, b) el crecimiento demográfico como un resultado del fenómeno migratorio. Desde su inicio, en la década de los setenta, Cancún ha sido considerado como la principal fuente de ingresos y empleo y esto se ha visto reflejado en el crecimiento del Producto Interno Bruto (рів) y de otros indicadores económicos del estado. Para el 2004, la participación porcentual en la tasa de empleo fue de $75.9 \%$ derivado del aumento en el número de cuartos de hospedaje, así como de establecimientos de preparación y servicios de alimentos y bebidas. En el 2006, se registraron un total de 1,533 negocios, incluyendo restaurantes, bares, cafeterías, discotecas; mientras que la ocupación hotelera en 2004, 2005 y 2006 fue de 76.5\%, 69.8\% y 73.6\%, respectivamente (Sectur, 2007).

Con relación al incremento de la afluencia de visitantes, en 2005 se registró un total de 1,358,434 visitantes, y 1,238,737 para 2006 (Daltabuit et al., 2000; INEGI, 2007; Sectur, 2007). Si bien estos datos permiten inferir que la actividad turística contribuyó a la generación de empleo e 
ingreso, los beneficios económicos de esta actividad tienen una trascendencia insuficiente en las zonas marginadas (Daltabuit et al., 2000). Los puestos de trabajo ocupados por la población local son escasos debido a que el nivel de escolaridad es bajo y no reúne los requisitos que exige el turismo internacional. Otra repercusión importante fue el crecimiento poblacional, resultante del proceso migratorio tanto rural como urbano.

En la actualidad, el crecimiento anual de la población de Quintana Roo es de $4.1 \%$, convirtiéndose en la entidad con el mayor crecimiento poblacional a nivel nacional. Las zonas dominadas por la actividad turística han recibido una atención prioritaria del Estado y del capital multinacional. En este sentido, el impacto de los procesos de globalización en Quintana Roo ha contribuido a una gran desigualdad social, aunada a una diferenciación cultural que es evidente en las tres regiones de la entidad: en la región norte del estado se localizan los grandes centros turísticos y es donde residen principalmente los inmigrantes; la región centro está habitada, principalmente, por la población de origen maya; mientras que en la región sur se encuentran tanto grupos de inmigrantes como la población de la capital, Chetumal, donde trabajan en la estructura administrativa y política del estado. En resumen, la actual estructura del estado muestra una clara diferenciación en función de la economía y sus diferentes sectores: primario, secundario y terciario, este último representado por el turismo (mapas Ia y $\mathrm{Ib}$ ).

\section{Metodología}

El estudio fue realizado en la península de Yucatán, que para propósitos de esta investigación, comprende los municipios de Felipe Carrillo Puerto, Tulum en Quintana Roo, incluyendo la comunidad de Punta Laguna que se encuentra dentro del Área de Protección de Fauna y Flora Otoch Ma'Ax Yetel Kooh (APfF). Por su ubicación geográfica, el ApfF se encuentra en los límites de los estados de Quintana Roo (municipio de Solidaridad) y Yucatán (municipio de Valladolid), pero administrativamente, pertenece a Valladolid, en el estado de Yucatán (Conanp, 2006). Se eligió Punta Laguna porque, por un lado, se encuentra dentro del territorio quintanarroense y, por otro, sus relaciones sociales para el desarrollo del ecoturismo se han establecido con operadoras turísticas de Cancún, Tulum y Playa del Carmen de Quintana Roo.

Para identificar y analizar las políticas turísticas y los actores sociales como factores que impulsan el desarrollo del ecoturismo en la zona maya se utilizó la técnica de muestreo "bola de nieve" (Román, 2007). Esta técnica permitió formar una red de informantes a través de la aplicación de un cuestionario previamente diseñado para la recolección de los datos 


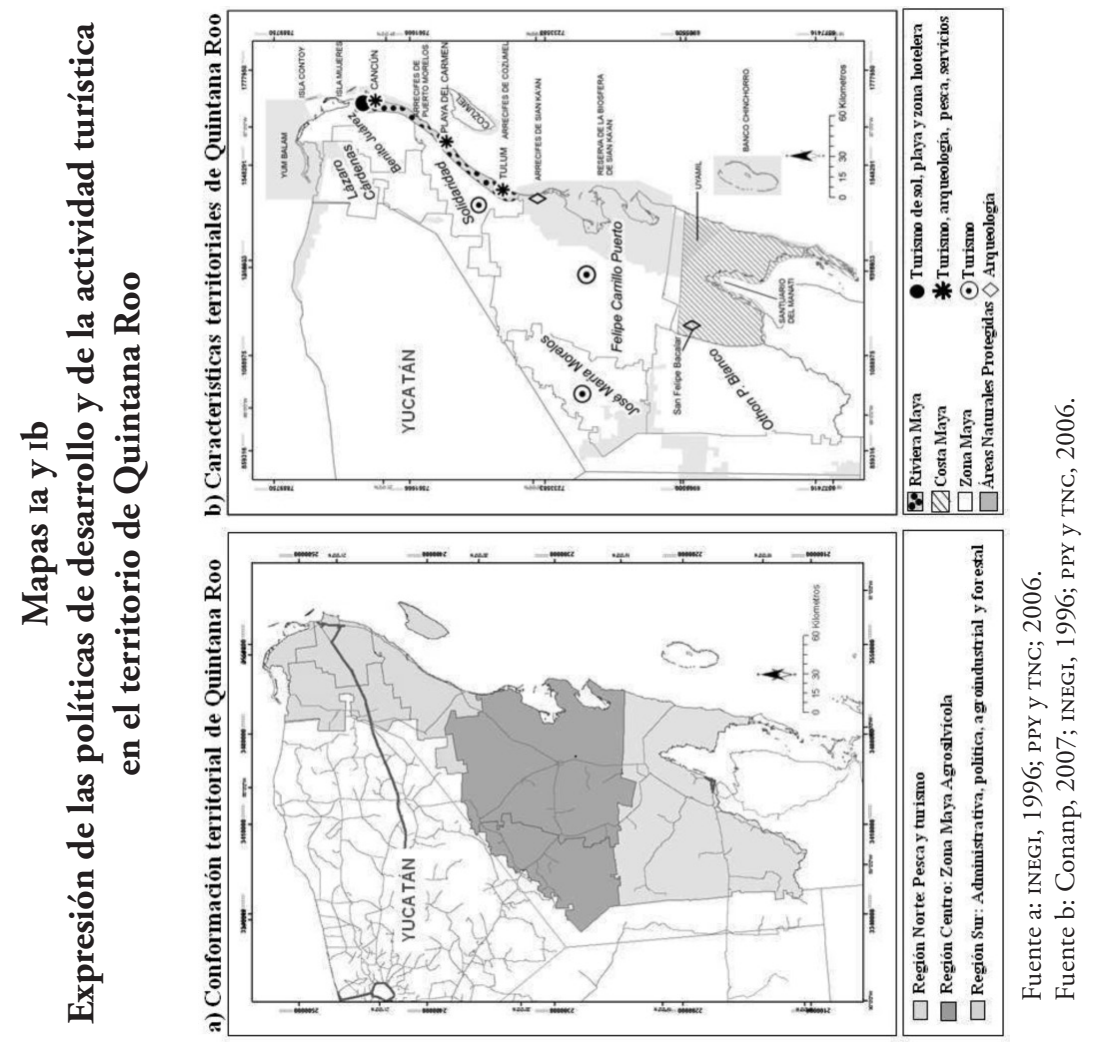


y que se dirigió principalmente a los representantes de organizaciones gubernamentales de los tres niveles (federal, estatal y municipal), organizaciones no gubernamentales (internacionales y regionales), operadoras turísticas y organizaciones locales en la zona maya de Quintana Roo. El trabajo de campo se realizó en el periodo de octubre a noviembre de 2008 y enero de 2009. Se aplicaron un total de 48 entrevistas distribuidas de la siguiente manera: 26 a funcionarios de dependencias gubernamentales, ocho a representantes de las ONG, siete a operadores turísticos y siete a integrantes de organizaciones comunitarias. La aplicación de las entrevistas tuvo una duración de una hora aproximadamente, con la finalidad de conocer las dependencias y organizaciones vinculadas al ecoturismo, así como sus objetivos y estrategias que utilizan para impulsar proyectos ecoturísticos. Se realizaron análisis descriptivos con el programa Estadístico para Ciencias Sociales spss (versión 15.0). Adicionalmente, se utilizó el programa Ucinet (versión 6.18), para representar gráficamente con quién se vinculan los actores para trabajar con ecoturismo, para lo cual se utilizó un indicador individual (el grado de centralidad) para conocer el número de actores a los que un solo actor está directamente vinculado (Borgatti, 2002; Velázquez y Aguilar, 2005). Asimismo, se calculó el indicador de densidad de la red para conocer el valor de porcentaje de conectividad de la misma; en otras palabras, la densidad es la medida expresada en porcentaje del cociente formado por las relaciones existentes entre las que posiblemente pudieran existir. A pesar de que graficar las interacciones de un grupo de actores no es suficiente para obtener un análisis profundo de cada individuo dentro de una red, la naturaleza propia de los datos utilizados (cualitativos) permitió un análisis descriptivo. (Velázquez y Aguilar, 2005).

\section{Resultados}

\subsection{Actores involucrados en el desarrollo del ecoturismo}

Del total de entrevistados (48), 81.3\% correspondió al género masculino y $18.8 \%$, al femenino. Se pudo apreciar una representación desequilibrada en el número de individuos y el tipo de posición que ocupan en las dependencias gubernamentales, organizaciones y operadoras ya que del total de los entrevistados, y que ocupan cargos directivos, $88.4 \%$ son hombres y únicamente $11.5 \%$ está representado por mujeres. Los actores identificados se clasificaron en: a) actores internacionales (agencias internacionales, las ONG y organizaciones sociales), b) actores nacionales (gobiernos nacionales, iniciativa privada, y las ONG nacionales) y, c) actores locales (pobladores locales, autoridades y administradores regionales), 
por lo que en el presente estudio sólo se identificaron los principales actores que inciden en esta actividad, que se clasificaron como: Actor 1: dependencias gubernamentales (federal, estatal y municipal; Actor 2: organizaciones no gubernamentales (internacional y regional); Actor 3: operadoras turísticas y, Actor 4: organizaciones comunitarias que hacen referencia a las cooperativas turísticas. Estos actores desempeñan un papel preponderante en la puesta en marcha de proyectos de ecoturismo; sin embargo, políticas y estrategias siguen los lineamientos de las agencias internacionales: el BM, el BID y el Fondo Monetario Internacional (FMI) que han promovido la propuesta de desarrollo sustentable con el supuesto de proveer beneficios ambientales, socioeconómicos y socioculturales a nivel local y nacional. El documento "Protect Areas economics and Policys: linking conservaction and sustainable development" del вм еs un ejemplo de ello, ya que describe los lineamientos para una adecuada gestión de los recursos económicos y asuntos políticos de las Áreas Naturales Protegidas.

\subsubsection{Actor 1: Dependencias gubernamentales}

En el contexto de la zona maya se reconoce la presencia de por lo menos trece dependencias gubernamentales que intervienen en el ecoturismo: la Secretaría de Medio Ambiente y Recursos Naturales (Semarnat) y sus distintas unidades administrativas: Comisión Nacional de Áreas Naturales Protegidas (Conanp); Comisión Nacional Forestal (Conafor) y la Procuraduría Federal de Protección al Medio Ambiente (Profepa) que están encargadas de regular la forma de uso de los recursos naturales. Existen, además, otras dependencias como la Secretaría de Turismo (Sectur), la Comisión Nacional de Desarrollo Indígena (CDI), la Dirección de Desarrollo Económico y el Fondo Nacional de Apoyo a Empresas de Solidaridad (Fonaes), la Secretaría de Desarrollo Social (Sedesol) y la Secretaría de Agricultura, Ganadería, Desarrollo Rural y Alimentación (Sagarpa), así como el Instituto Nacional de Antropología e Historia (INAH).

A nivel estatal destaca la participación de la Secretaría de Desarrollo Turístico (Sedetur), que es la encargada de coordinar y concluir procesos de planeación gubernamental orientados al desarrollo económico y social de las regiones del estado, se vincula con los grupos sociales interesados y promueve la canalización de los recursos públicos a los programas prioritarios, manteniendo en forma permanente un sistema de medición y difusión de los resultados.

En el ámbito municipal se identificaron las siguientes dependencias: Dirección Municipal de Turismo, presidencia municipal de Valladolid, Dirección de Administración, Dirección de Participación Ciudadana en 
el municipio de Felipe Carrillo Puerto, Dirección de Desarrollo Económico vinculada a la presidencia municipal de Tulum y la Dirección de Desarrollo Urbano y Ecología encargada de la infraestructura urbana y rural, teniendo como prioridad el control y destino de residuos sólidos para mantener la imagen del municipio. Estas dependencias poseen discursos similares en sus propuestas de desarrollo, los objetivos y estrategias que persiguen se centran en promover la conservación y el desarrollo socioeconómico a través del aprovechamiento sustentable de los recursos naturales.

\subsubsection{Actor 2: Organizaciones no gubernamentales (ONG)}

En este grupo se identificaron ocho actores: una ONG internacional representada por el Programa de Participación Comunitaria para la Conservación (сомраст, por sus siglas en inglés) a través del Programa de Naciones Unidas para el Desarrollo (PNUD, 2006), y siete ONG regionales: Amigos de Sian Ka'an, Ximbal Turismo Sustentable, Community Tour Sian Ka'an, Ecociencia, Centro Ecológico de Sian Ka'an y Herencia Punta Allen ubicadas en Quintana Roo. Estas organizaciones colaboran en trabajos relacionados con el ordenamiento territorial, logística y proyectos ecoturísticos con las ong del estado de Yucatán como Pronatura Península de Yucatán (PPY) y Proenlaces. Mientras que las ONG regionales tienen objetivos similares, ya que todas contemplan en sus programas los elementos de conservación y desarrollo socioeconómico a través de apoyos financieros, capacitación, mediación y promoción del ecoturismo; en el caso del сомраст, sus objetivos se centran en la conservación y valoración de la biodiversidad; el fortalecimiento de los conocimientos de la cultura maya; la autogestión y la equidad a través de apoyos financieros, capacitación y mediación en las comunidades del área de influencia de la Reserva de la Biósfera Sian Ka'an (RBSK).

\subsubsection{Actor 3: Operadoras turisticas}

En cuanto a las operadoras turísticas se identificaron siete procedentes de Cancún, Tulum y Playa del Carmen, entre las más importantes destacan: Alltournative, Tour operadora Eco-Colors, Agencia Via Vai, Maya Moom, Tour operadora Cesiak, Sabana Travel, Operadora Manzano Expeditions que ofrecen excursiones a las comunidades que se encuentran dentro de las RBSK y del Área de Protección de Flora y Fauna Otoch Ma'Ax Yetel Kooh (APFF). En este contexto, 86\% de los entrevistados de las operadoras mencionó que sus objetivos se centran en el desarrollo socioeconómico de la región y $14 \%$ manifestó que persigue el desarrollo comunitario a 
través del turismo sustentable. Alltournative es una de las operadoras que integra entre sus actividades los conceptos conservación y desarrollo socioeconómico; se fundó en 1999 con sede en Cancún y con oficinas en Playa del Carmen y Tulum; sus objetivos son crear proyectos de ecoturismo que conserven y protejan la flora y fauna de la región y que mejore el modo de vida de los habitantes de las comunidades locales coadyuvando en la conservación de las tradiciones culturales de la comunidad.

\subsubsection{Actor 4: Organizaciones comunitarias}

En la zona de estudio se encontraron ocho organizaciones comunitarias, entre ellas, cuatro cooperativas turísticas situadas en la comunidad de Punta Allen (Las Boyas, Vigía Grande, Punta Allen y Gaytanes), dos en Muyil (Cooperativa Conjunto Aluxes y Uyoochel Maya), una en Punta Laguna (Cooperativa Najil Tucha) y una Asociación denominada Herencia de Punta Allen. Estas organizaciones surgieron en la década de los noventa como una alternativa para complementar el ingreso familiar y también por el interés de algunas dependencias gubernamentales y diversas ONG, de trabajar en pro del desarrollo socioeconómico y la conservación de los recursos naturales en la región. Los objetivos de estas organizaciones se centran en fomentar el desarrollo socioeconómico y promover el turismo comunitario. Entre las actividades que se desarrollan se encuentran la pesca deportiva, recorridos en lancha, senderos interpretativos, recorrido en la zona arqueológica, observación de flora y fauna nativa.

\section{Estrategias de los actores para el desarrollo del ecoturismo}

Una primera aproximación al análisis de las estrategias de los actores para impulsar el ecoturismo revela dinámicas distintas. Las dependencias gubernamentales diseñan sus estrategias con base en los lineamentos del BM, FMI y del BID que han sido los impulsores de la política neoliberal, a través de las reformas estatales en el ámbito gubernamental y de implementación de las reglas de competitividad en las negociaciones globalizadas del intercambio económico trasnacional. El discurso de estos organismos se centra en el desarrollo sustentable, del cual se derivan las políticas nacionales y regionales, las leyes y las estrategias de desarrollo de ecoturismo que se llevan a cabo a través de las dependencias gubernamentales y algunas ONG.

Las operadoras turísticas y las organizaciones comunitarias basan sus estrategias en la planeación y la promoción de los productos turísticos (cuadro 1). Las estrategias de las dependencias gubernamentales se llevan a cabo a través del Programa de Conservación para el Desarrollo Susten- 
table (Procodes), de la Conanp, del Programa Ecoturismo en Zonas Indígenas (PEZI) y del Programa de Desarrollo Forestal (Prodefor) de la Conafor. Estos programas, aunque diferentes en cuanto a cobertura poblacional, se confluyen en sus objetivos: a) generar oportunidades productivas alternativas que contribuyan a mejorar la calidad de vida de los habitantes en el entorno de las áreas protegidas y otras modalidades de conservación, b) generar ingresos económicos a sus beneficiarios, promover la organización comunitaria y la permanencia de los pobladores en sus comunidades; además, sus acciones coinciden en la forma de elaborar sus programas y planes de acción para lograr sus objetivos, a menudo, a través de la acción contrapartida entre los tres niveles de gobierno. Otra estrategia de estas dependencias es la de carácter normativo, para lo cual se han creado los siguientes mecanismos: la Guía de Normatividad Ambiental aplicable al ecoturismo y la Norma Mexicana NMX-AA-I 33-SCFI-2006.

Las estrategias de las ONG, en materia de ecoturismo, van desde la planeación, gestión, vinculación y promoción de los proyectos ecoturísticos a nivel regional, así como la mediación de conflictos y asesoría en la preparación de proyectos comunitarios, sobre todo en las localidades más distantes a las ANP. Entre ellas destaca la Community Tour Sian Ka'an, cuyo objetivo es transmitir a los visitantes los valores de un Sitio de Patrimonio de la Humanidad como la Reserva de Sian Ka'an. Esta organización fue creada por la Cooperativa Muyil Conjunto de Aluxes con la colaboración de RARE Internacional para ser manejada a nivel local. Su estrategia consiste en actuar como una empresa integradora de cooperativas turísticas para ofrecer servicios turísticos en Muyil y Punta Allen. Actualmente, esta organización ofrece seis diferentes tours privados y grupales en el interior de la RBSK.

A diferencia de los otros actores, las operadoras enfocan sus estrategias en la promoción del ecoturismo a nivel nacional e internacional, la creación de mecanismos para ofertar las actividades ecoturísticas y la comercialización de paquetes turísticos directamente a los viajeros, o con la colaboración de intermediarios, la vinculación entre los visitantes y los hoteles, y en el caso particular de la operadora Alltournative, su estrategia, además de las mencionadas, es la inversión en infraestructura turística y el fortalecimiento de las capacidades de los socios de los proyectos ecoturísticos.

Las organizaciones comunitarias utilizan como estrategias la organización y la planeación de los tours que se realizan a través de paseos en lanchas, pesca deportiva, recorridos en senderos interpretativos, entre otras. Aunado a esto, realizan la gestión de los permisos para el ejercicio de estas actividades turísticas ante la RBSK y APFF Otoch, así como la participación en convocatorias para acceder a apoyos gubernamentales para la adquisición de equipos, construcción y mejora de infraestructura 


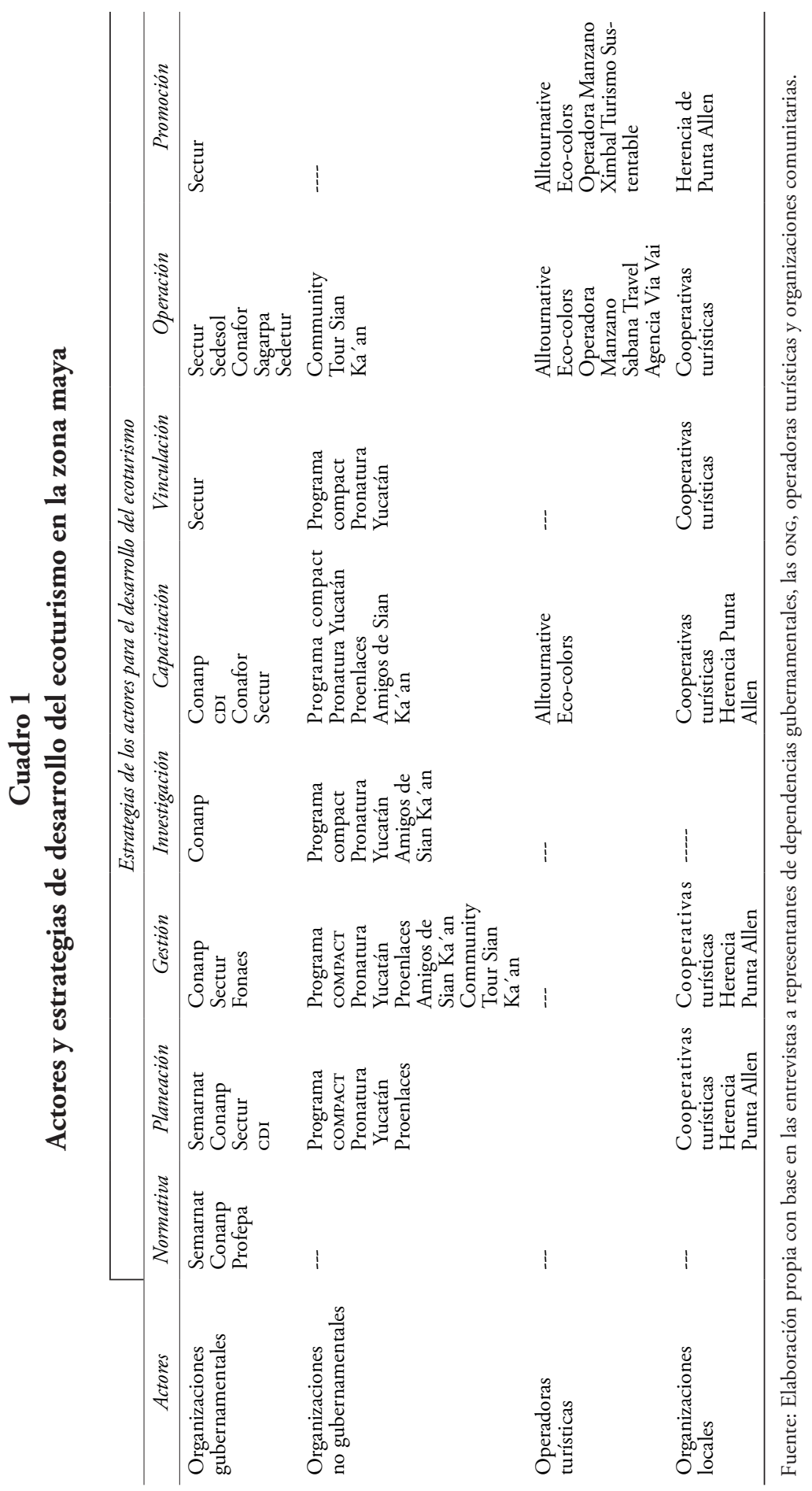


turística y capacitación. Además, participar en cursos de capacitación promovidos por las dependencias gubernamentales y asesoría del Programa compact-Pnud, Amigos de Sian Ka'an, Ximbal Sustentable y Proenlaces y Pronatura Península de Yucatán.

\section{Cobertura y tipos de apoyos}

Las dependencias gubernamentales y organizaciones tienen claramente definida su cobertura en los lineamientos de las reglas de operación de sus programas. Por lo general, los programas de apoyo están focalizados, por ejemplo, los apoyos del Procodes se dirigen a los municipios inmersos en la RBSK y el APFF Otoch Ma'Ax; mientras que el PEZI se dirige a comunidades con presencia indígena y, Prodefor, a pequeńos propietarios de bosques. El número de beneficiarios varía de acuerdo con el tipo de programa y de la población objetivo, según sus reglas operativas. Debido al carácter focalizado de estos programas, la distribución de los apoyos es inequitativa ya que no cubre las necesidades básicas de la población de manera integral. El vínculo que se establece con los grupos organizados se da a través del Sistema para el Desarrollo Integral de la Familia (DIF) además de visitas periódicas a las comunidades, reuniones, asambleas, convenios con asesores externos y otras instancias municipales. En relación a los actores que apoyan proyectos ecoturísticos, 92.6\% de los entrevistados de las dependencias gubernamentales respondió que apoya esta actividad en diferentes rubros y en coordinación con otras instancias de gobierno y las ONG. Mientras que todas las ONG operadopras y organizaciones comunitarias contribuyen al desarrollo del ecoturismo en tres rubros principales: recursos financieros, capacitación y promoción (figura I). La procedencia de los recursos usados $\mathrm{p}$ ara apoyar el ecoturismo por parte de las dependencias gubernamentales es principalmente mixto, es decir, en contraparte con otras instancias de gobierno o con las ONG, esto es, $59.3 \%$ proviene de estas organizaciones, y $40.7 \%$ son recursos concedidos por el Gobierno Federal. Mientras que 14.3\% de los recursos otorgados por las ONG son propios y $85.7 \%$ son mixtos. Asimismo, la procedencia de los recursos de las operadoras se dividen en mixtos (14.3\%) y recursos propios $(85.7 \%)$. En cambio, $57.1 \%$ de los recursos de las organizaciones proceden de contrapartes y $42.9 \%$, de recursos propios.

Por lo general, la divulgación de los apoyos a los proyectos de ecoturismo es a través de convocatorias, visitas periódicas a las comunidades, radio y folletos. En varios casos, incluyendo el PNud y el Programa de Pequeñas Donaciones del Fondo Mundial, México. El acceso a estos apoyos requiere que los grupos de base comprueben que están legalmente constituidos bajo alguna forma de organización social, ya sea como 


\section{Figura I}

\section{Tipos de apoyo otorgados a programas de ecoturismo por los diferentes actores}

- Financiero, capacitación y mediación $\square$ Capacitación $\square$ Promoción

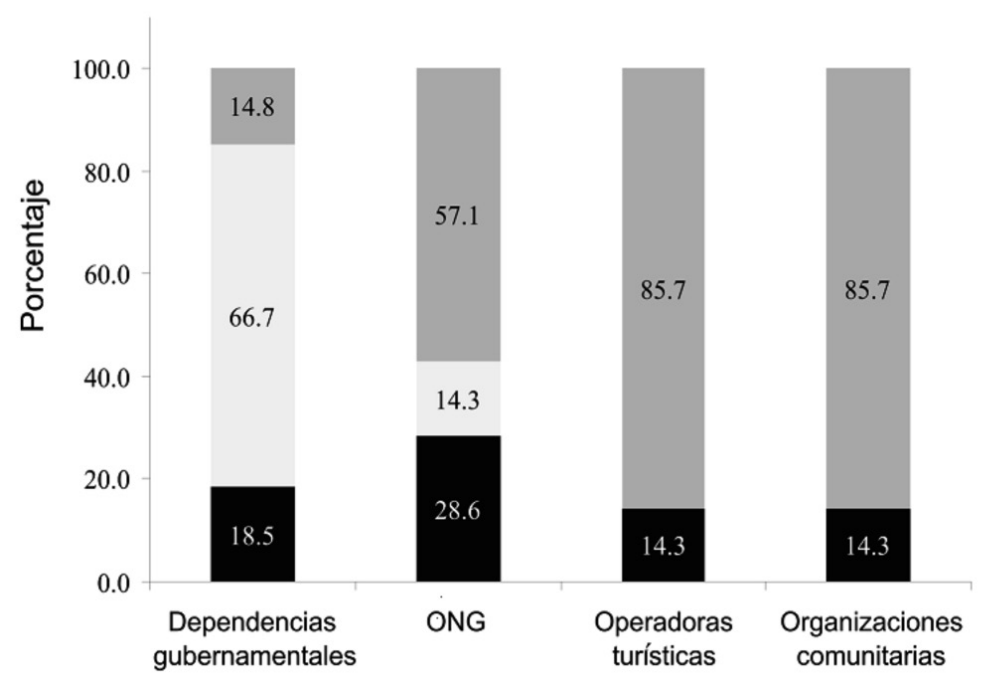

Fuente: Elaboración propia con base en el trabajo de campo.

cooperativa o asociación civil y que cuentan con permisos pertinentes para la prestación de servicios turísticos u otros usos relacionados con los recursos naturales, lo que pone en desventaja competitiva a algunos grupos locales organizados debido a usos y costumbres (principalmente en la zona maya) ya que, aunque necesitan apoyo, quedan fuera como beneficiarios del programa. Lo anterior se explica porque las comunidades mayas de la región acostumbran organizarse con parientes y en ocasiones con amigos muy cercanos, como compadres, para trabajar sus sistemas productivos (Estrada, 2005). Sin embargo, esta forma tradicional de organización no está mediada por un notario público que dé fe o legalice a la organización, lo cual es un requisito indispensable para acceder a los programas referidos. Al recibir los apoyos, los beneficiados adquieren responsabilidades que deberán cumplir, acatando los acuerdos establecidos en las reglas de operación, tales como ejecutar y comprobar los recursos económicos recibidos, asistir a las capacitaciones que se les ofrecen, participar en reuniones y actividades comunitarias. Mientras que las responsabilidades de las dependencias y organizaciones hacia los grupos beneficiados consisten en realizar diagnósticos, supervisar la ejecución de los 
recursos económicos otorgados, dar seguimiento técnico y aplicar las normas para el buen funcionamiento de estas actividades.

\section{Aporte de los programas de apoyo a las organizaciones comunitarias}

Con respecto a las inversiones a proyectos ecoturísticos, СОмРACT destina $27 \%$ de su presupuesto al fortalecimiento de las organizaciones comunitarias a través de programas de capacitación, estudios técnicos, equipamiento e infraestructura. El apoyo para capacitación y asesoría técnica, se otorga con el fin de fortalecer la capacidad administrativa y organizacional de los grupos proponentes. Durante el periodo 2001-2008 se invirtieron aproximadamente 4,000,000 de pesos para el ecoturismo y la mayor parte de este monto se ejecutó en actividades de capacitación y en compra de equipos, por ejemplo, motores para las embarcaciones turísticas, así como en la realización de estudios en temas relacionados con capacidad empresarial, potencial turístico y sondeos de mercado (PNUD, 2006). Entre 2004 y 2009 el Procodes invirtió aproximadamente 1,300,000 pesos en proyectos ecoturísticos para la realización de estudios técnicos, actividades de capacitación y adquisición de equipos e infraestructura. La inversión de este programa se ha dirigido principalmente a proyectos comunitarios (figura II).

\section{Figura II}

\section{Rubros y porcentaje de recursos aplicados en actividades de ecoturismo del 2001-2009 por el Programa COMPACT-PNUD y Procodes, en Quintana Roo}

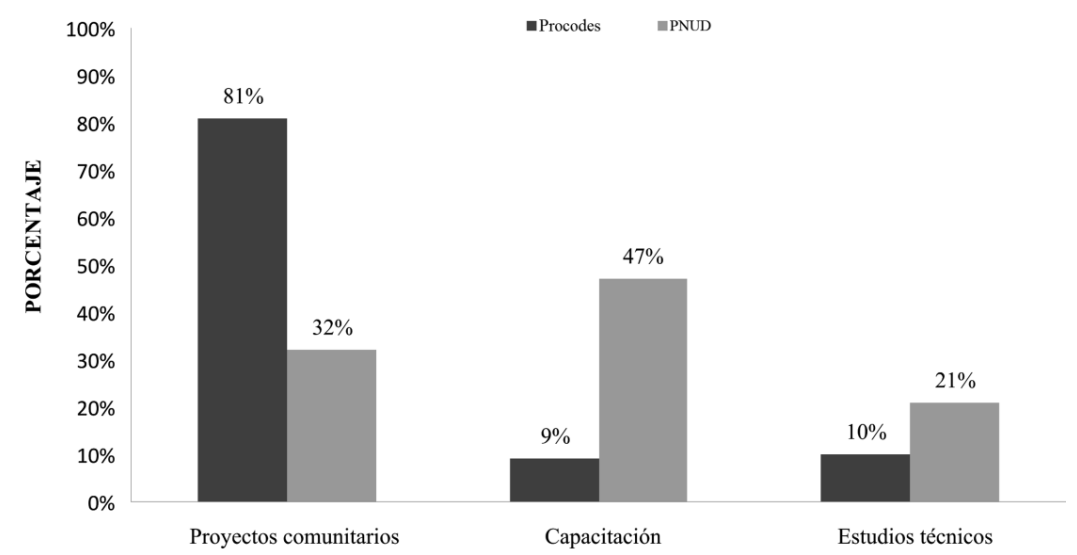

Fuente: Elaboración propia con base en los datos de COMPACT-PNUD 2001-2009 y Conanp-Procodes (2006-2007). 
El PEZI, realizó inversiones de más de 3,000,000 de pesos entre 2001 y 2005 , equivalente a $2.6 \%$ de la inversión total a nivel nacional. Este programa apoya proyectos ecoturísticos con montos de hasta 1,500,000 pesos para la construcción de infraestructura, adquisición de equipos y materiales para instalaciones y servicios, asistencia técnica, capacitación, estudios técnicos, difusión y promoción.

\section{Principales beneficiarios del ecoturismo}

Con base en las estrategias para el desarrollo del ecoturismo (Agenda 21, Política de Desarrollo Rural, LRDS y PND 2007-2012, que señalan como prioridad coadyuvar en la atención a los problemas de marginación y pobreza para generar un desarrollo económico a partir de prácticas amigables con la naturaleza, los principales beneficiarios del ecoturismo deberían ser las cooperativas turísticas, pequeños propietarios, grupos indígenas y pobladores locales, sin embargo, se encontró que los que están capitalizando esta actividad son las empresas privadas representadas por las agencias receptivas situadas en la Riviera Maya (mapa Ib). A nivel regional, es decir, con influencia en Quintana Roo y en otros lugares de la península de Yucatán; las agencias líderes son mexicanas pero existen algunas de propiedad nacional aunque con una mayor inversión extranjera como Apple Vacation, Best Day, Olympus y Hola Tours. Estas últimas se encargan de captar el turismo de países como Italia, Alemania y Estados Unidos y promover los paquetes vacacionales con todos los servicios incluidos. Aunque es difícil establecer con precisión sus ganancias, se estima que pueden rebasar a un billón de dólares anuales únicamente por trasladar al turista desde su país de origen a Quintana Roo. Por otro lado, están las operadoras turísticas que representan a las agencias de viajes y que interceden entre los turistas y las cooperativas. Sus servicios incluyen el transporte de ida y vuelta, guías capacitados, alimentación y recorridos. En términos de ganancia, por ejemplo, el traslado hacia Punta Allen por parte de la operadora turística tiene un costo de 300 dólares por persona. Otros actores que no están respaldados bajo algún tipo de organización son los intermediarios, quienes prestan servicios a los turistas que no cuentan con algún paquete turístico. El servicio que ofrecen es el traslado terrestre en camionetas con capacidad hasta para 14 personas. La renta del transporte varía, dependiendo de las condiciones del camino de acceso a la comunidad, pero por lo general es de 150 dólares. La comercialización de los productos ecoturísticos de las cooperativas depende de los actores arriba mencionados, por ejemplo, una de las comunidades con mayor disponibilidad de servicios para el turismo nacional y extranjero es la comunidad de Punta Allen. Esta localidad tiene un 
mayor flujo de visitantes debido a que dispone como atractivo principal un recorrido de aproximadamente tres horas para la observación de manglares y fauna silvestres (aves, delfines, cocodrilos, entre otros), así como la práctica de snorkel y la pesca deportiva que se desarrolla en el periodo de junio a diciembre.

Este recorrido se realiza en embarcaciones con capacidad para seis pasajeros con un costo de 150 dólares por embarcación, es decir, que cada turista paga 25 dólares. Además del recorrido, los guías dan las indicaciones a los turistas sobre el servicio de alimentación ofertado únicamente por dos de las cuatro cooperativas (Punta Allen y Vigía Grande) y el costo de la alimentación varía entre nueve dólares para el desayuno y 13 dólares para comida. Por otra parte, Punta Allen cuenta con servicio de hospedaje manejado por residentes locales y por extranjeros. De las cooperativas existentes, la cooperativa turística Las Boyas y la cooperativa Pesquera Vigía Chico ofrecen este servicio a un costo que varía de 50 a 70 dólares, dependiendo de la temporada del año.

Por otro lado, a la comunidad de Muyil llega un promedio de 48 visitantes por día y mensualmente, el número de visitantes promedio es de 770. Las cooperativas Aluxes y Uyoochel Maya ofrecen los servicios turísticos para la observación de aves, caminatas en los senderos, recorridos en lanchas por los canales de la laguna Chunyaxché, centros arqueológicos y senderos explicativos. Para ofrecer estos servicios las cooperativas cuentan con diez lanchas (seis de la Cooperativa Aluxes y cuatro de Uyoochel Maya). Aunque éstas no cuentan con datos precisos acerca del flujo de turistas, tan sólo en 2009 recibieron un total de 5,713 (de acuerdo con los registros de la RBsK). En contraste a lo que ocurre con Punta Allen, las cooperativas de Muyil no cuentan con infraestructura turística para ofrecer servicios de restaurant y hospedaje y estos servicios se encuentran a 19 kilómetros de Muyil, en Tulum.

Punta Laguna es otra de las comunidades que cuenta con una cooperativa denominada Najil Tucha, que posee una reducida infraestructura turística que consta de un restaurante, caseta de recepción y letrinas. Los servicios que ofrece consisten en un recorrido por la selva dentro de las APFF para observación de fauna silvestre, paseo en canoa por la laguna, la tirolesa y ceremonia maya. Se estima que la cooperativa Najil Tucha recibe aproximadamente cuatro grupos por semana, lo que corresponde a un total 240 visitantes por mes; sin embargo, hay un convenio de exclusividad entre la cooperativa y la operadora Alltournative. El convenio permite a la operadora llevar turistas para visitar a la comunidad por un costo de 25 dólares por persona. Los socios de esta cooperativa fungen como prestadores de servicios de la operadora como guías y encargados del restaurante recibiendo 25 y 15 dólares diarios, respectivamente. Res- 
pecto a ingresos, la situación de esta cooperativa es compleja, ya que sus actividades dependen de la llegada de turistas a través de la operadora o de turistas nacionales (paracaidistas) que llegan sin aviso previo o contratando algún tipo de paquete de alguna operadora.

Considerando los beneficios generados por el ecoturismo en las comunidades de estudio, el ingreso que las cooperativas obtienen a partir de esta actividad es mínimo, ya que $50 \%$ de las ganancias queda en la cooperativa y el otro $50 \%$ se emplea para gastos de operación (mantenimiento de embarcaciones y de la infraestructura con la que se cuenta, compra de combustibles, entre otros).

Para conocer los principales beneficiarios del ecoturismo se consideró el siguiente ejemplo con datos de costos por persona: realizar un tour en comunidades de la Riviera Maya con atractivo turístico implicaría que una agencia de viajes con sitio de operaciones en Quintana Roo perciba 772.8 dólares; para trasladar a un turista desde Estados Unidos a un hotel de Cancún, la operadora turística ofrece tours por un precio base de 146 dólares; el intermediario (quien ofrece el tour o únicamente el traslado terrestre de 14 personas) percibe 150 dólares; mientras que los tours de las cooperativas por grupos de seis personas como mínimo tiene el mismo costo de los intermediarios, es decir, que el precio por persona es de 25 dólares (figura III). De tal manera, se concluye que la mayoría de las cooperativas no cuentan con un registro o datos precisos del número de turistas que visitan sus comunidades, sin embargo, la mayor parte de las ganancias obtenidas por la actividad turística se distribuyen entre las agencias de viajes y las operadoras turísticas.

\section{Impacto del ecoturismo desde la perspectiva de los actores}

Con respecto al impacto causado por el ecoturismo, 96.3\% de los entrevistados manifestó que el ecoturismo genera impacto negativo en el área donde trabajan, refiriéndose a conflictos y divisiones que ocurren dentro de la comunidad, a raíz de que la actividad beneficia a un número reducido de familias; siendo que los no se benefician con la actividad se encuentran fuera de las regiones prioritarias de los programas de apoyo o, bien, son las que no están bajo alguna forma de organización.

Los impactos ambientales mencionados fueron la contaminación por basura y el desmonte de áreas con vegetación para la construcción de infraestructura turística. Sólo $44.4 \%$ de los entrevistados manifestó que cuentan con algún método de monitoreo y evaluación de impacto. Entre los métodos mencionados destacan las visitas a las comunidades, encuestas, reuniones bimestrales y entrevistas a los residentes de las comunidades. 


\section{Figura III}

\section{Principales beneficiarios del ecoturismo en la zona de maya de Quintana Roo}

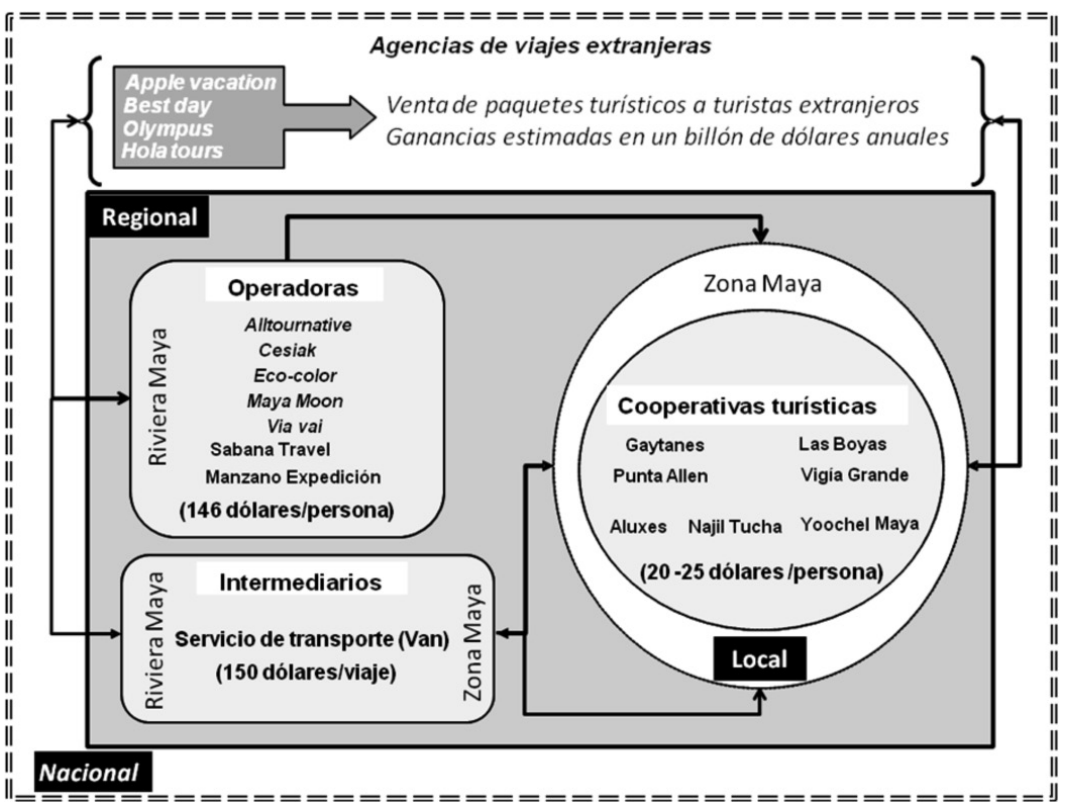

Fuente: Elaboración propia con base en Güemes (2008) y datos obtenidos en las cooperativas turísticas de la zona de estudio.

En la mayoría de los casos, los pobladores locales no participan en el proceso de monitoreo de impactos del ecoturismo.

Desde la opinión de los entrevistados, se puede inferir que el ecoturismo que se desarrolla en la zona de estudio contrasta con los supuestos teóricos, sobre todo, en lo que se refiere a la generación de beneficios económicos y sociales para las comunidades; que sea de bajo impacto sobre los recursos naturales y que promueva la conservación. En el plano económico, aunque esta actividad puede generar ingresos complementarios para las familias involucradas, se ha demostrado anteriormente que son las agencias de viajes y las operadoras turísticas los que se benefician económicamente. En términos sociales, la realidad en las comunidades reveló que existen problemas de división de los pobladores locales ya que unos participan en la actividad y otros no tienen la oportunidad de participación, esto, debido a la falta de capacitación sobre todo en idiomas diferentes del maya y como guía turístico.

Con respecto a los objetivos de conservación, aunque los proyectos ecoturísticos establecen sus estrategias y normas para conservar el medio donde desarrollan sus actividades, el flujo turístico en las comunidades 
ha causado inconvenientes para los pobladores locales y ha deteriorado los caminos por el tipo de transporte que utilizan en los tours, por ejemplo, Punta Allen, a pesar de que se encuentra dentro de una área protegida, algunas operadoras han utilizado hasta 17 jeeps en un solo día de tour, aunado a ello, los turistas no respetan los límites de velocidad dentro de la comunidad.

\section{Vínculos entre los actores para apoyar el ecoturismo}

En el ámbito del ecoturismo a pesar de que existen mecanismos de coordinación para la elaboración de estrategias de financiamiento por parte de las dependencias gubernamentales, las empresas privadas y organizaciones sociales; la coordinación entre éstos en el área de estudio es ocasional y se basa principalmente en la influencia geográfica en la cual operan. En la red de actores se pueden observar tres tipos de relaciones: a) entre las dependencias gubernamentales y las ONG, que se facilita más por el apoyo financiero a proyectos de ecoturismo. También se propone a nivel de estados, como es el caso de las dependencias gubernamentales de Quintana Roo y las ong Pronatura y Proenlaces de Yucatán, ya sea para realizar trabajos de ordenamientos territoriales comunitarios, control de fauna, alternativas productivas como la apicultura, el diseño de productos ecoturísticos y manejo de energías renovables. En la mayoría de los casos, las ONG son portavoces de las dependencias gubernamentales y de las organizaciones comunitarias, b) la relación entre las ONG y organizaciones comunitarias que se condicionan para la capacitación de recursos humanos, mediación de conflictos y asesoría para la creación de empresas comunitarias y elaboración de propuestas que permiten el acceso a recursos económicos y, c) la relación entre las operadoras turísticas y las organizaciones comunitarias que se da en aspectos de promoción y venta de los paquetes turísticos y, en algunos casos, en la capacitación a los integrantes de las cooperativas.

Como se verá en la figura Iv, en la estructura de la red, los símbolos (nodos) representan a los actores; los rectángulos, a las dependencias federales, el triángulo, a la dependencia estatal; los rombos, a las municipales; los triángulos inversos, a las ONG internacionales; los triángulos rectángulos, a las ONG regionales; los hexágonos, a las operadoras turísticas y, los círculos, a las organizaciones comunitarias. La relación entre el número de interacciones que mostraron los diferentes actores a través del indicador individual de centralidad mostró que el actor con el mayor número de actores vinculados es la Conanp con $48.8 \%$, seguido por el CDI con $37.2 \%$, y PNUD con $32.5 \%$. Otras dependencias con un grado de centralidad importante son Semarnat con 23.2\%, Sectur con 23.5\% 


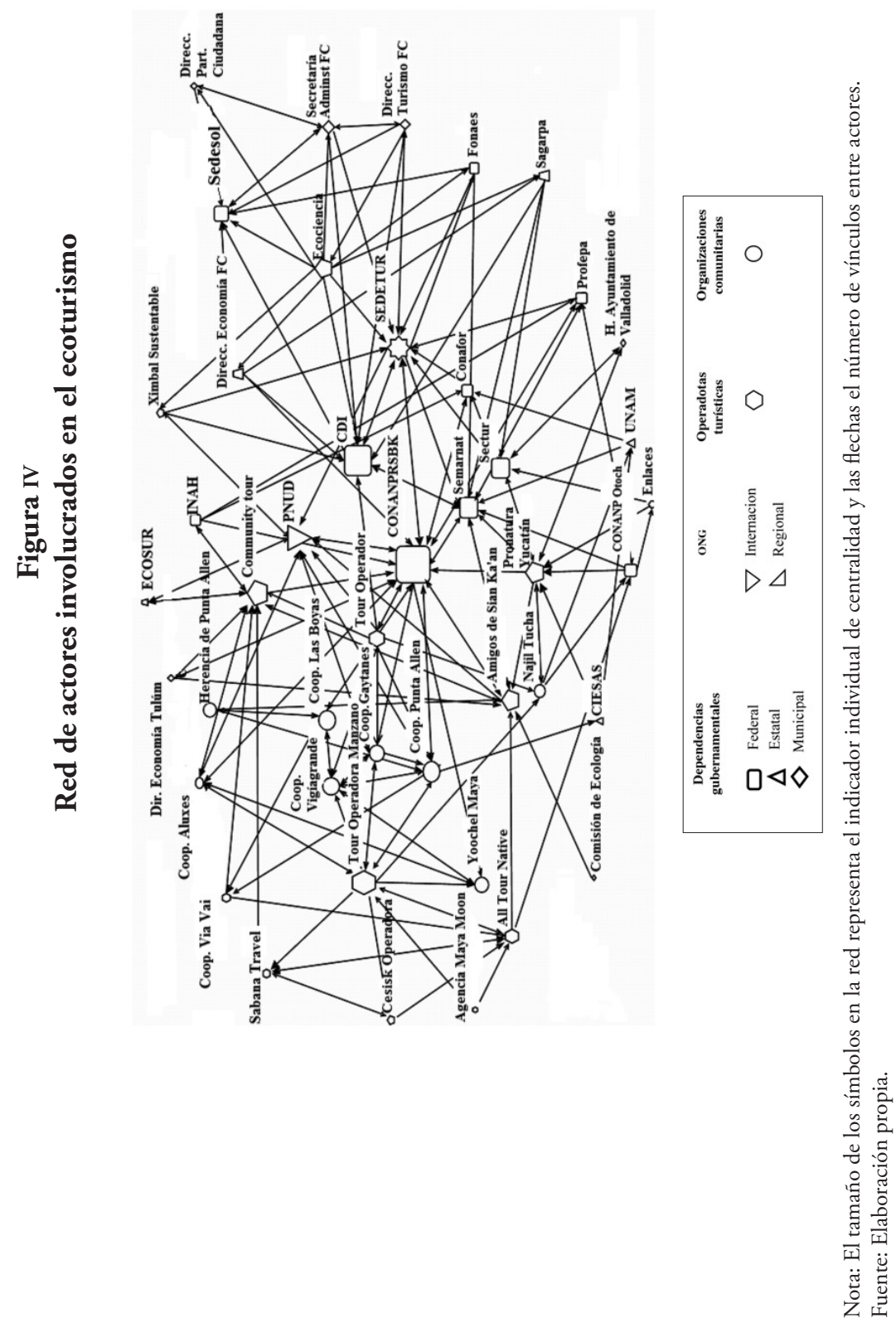


y Sedetur con $28 \%$. Al considerar el número máximo de relaciones existentes con respecto al número de relaciones posibles, el indicador de densidad para la red fue de $10.4 \%$ lo que indica una décima parte de los enlaces posibles.

\section{Característica de la relación existente entre los actores}

Con respecto al tipo de relación que se mantiene entre los diferentes actores, los entrevistados de las operadoras turísticas, 85.7\%, y de las organizaciones locales, $71.4 \%$, perciben una relación positiva pero con problemas eventuales. Para las ONG, el tipo de relación con los demás actores es armoniosa y sin mayores problemas, $71.4 \%$. La mitad de los entrevistados de las dependencias gubernamentales, es decir, $48.1 \%$ percibió una relación negativa por parte de las organizaciones comunitarias hacia ellas, sobre todo las que tienen un carácter normativo como son la Semarnat, Conanp y Profepa. Cabe resaltar que las relaciones entre las dependencias gubernamentales y los demás actores no ocurren sin la ausencia de tensiones. Para las organizaciones comunitarias, la relación con respecto a las dependencias gubernamentales (en su carácter normativo).y sus actividades (restringiendo el acceso y el uso a los recursos de las áreas protegidas) son consideradas negativas. Las dependencias se identifican como fiscalizadoras y reguladoras de las actividades tradicionales (caza, pesca, aprovechamiento forestal y extracción de productos no maderables del bosque) y turísticas (permisos), sobre todo en áreas protegidas.

\section{Discusión}

La zona maya de Quintana Roo representa un territorio de contrastes, por un lado, es una región con una alta riqueza de recursos naturales y culturales y, por otra parte, presenta un alto grado de marginación. Los pobladores de la zona maya han subsistido principalmente en la región con actividades relacionadas a la agricultura de subsistencia, la apicultura, la ganadería y las actividades forestales, y hasta hace tres décadas han adoptado el ecoturismo como una alternativa para mejorar sus ingresos $y$, en general, su nivel de vida. Sin embargo, algunas zonas no cuentan con los servicios básicos como educación, salud, agua potable, drenaje y luz, todos ellos, elementos indispensables para brindar un servicio de calidad en proyectos ecoturísticos.

El desarrollo del ecoturismo en la zona tiene su origen a partir de las estrategias de las dependencias gubernamentales y organizaciones ligadas al sector turístico. Las dependencias gubernamentales desempeñan un papel clave en la regulación del uso de los recursos naturales, estos actores 
se coordinan conjuntamente para establecer las estrategias generales basadas en propuestas de desarrollo, de agencias internacionales y las políticas nacionales de desarrollo del turismo que tiene como objetivo proponer acciones a corto y mediano plazo, para fortalecer la dinámica de las regiones turísticas y propiciar el desarrollo sustentable.

Las dependencias gubernamentales al adoptar las propuestas de desarrollo de las agencias internacionales accedan a apoyos financieros que posteriormente se destinan a las áreas focales de actuación. A pesar de que las ONG han tenido un papel fundamental y protagónico en el desarrollo del ecoturismo, la mayoría de estas experiencias han sido poco documentadas por lo que es complejo conocer su verdadero alcance. Sin embargo, al igual que los actores anteriores, sus estrategias coinciden en materia de conservación y en programas de capacitación, así que se puede considerar que sus intereses y acciones son relativamente similares. Otras ONG como Community Tour, es un caso particular, ya que a través de su figura jurídica accede a los recursos de las dependencias gubernamentales y agencias internacionales (PNUD) e integra sus intereses económicos fungiendo como una operadora turística la cual brinda servicios de traslado y vinculación con los hoteles de la Riviera Maya. En contraste, los objetivos e intereses de las operadoras turísticas son de carácter económico y, en menor medida, de conservación. En algunos casos las operadoras realizan inversiones para la mejora de infraestructura comunitaria y el fortalecimiento de las capacidades con la finalidad de ofrecer servicios de calidad a los turistas. Sin embargo, lo que podría ser visto como un apoyo al desarrollo comunitario, se traduce en un tipo de monopolio donde las operadoras que invierten en estas mejoras de capacitación e infraestructura dentro de las comunidades, posteriormente solicitan a las cooperativas la firma de un convenio de exclusividad, lo que genera dependencia tanto para la gestión como para la operación de la actividad por parte de las cooperativas.

Las organizaciones comunitarias centran sus objetivos en el desarrollo económico a través del ecoturismo. Estas organizaciones se crearon y han permanecido gracias al apoyo que reciben de los programas gubernamentales y el vínculo que establecen con las ONG internacionales y regionales, así como con las operadoras turísticas. Los apoyos recibidos se dirigen a rubros de infraestructura turística, capacitación, adquisición de equipos en cuestión operativa. Sin embargo, no existe un seguimiento o evaluación del proceso, de forma que persiste la dependencia de la asesoría externa para la elaboración de sus proyectos. Si bien, en estas organizaciones existe similitud en la manera de organización, hay una marcada diferencia en cuanto a la cantidad de organizaciones en los municipios y en las comunidades, número de personas involucradas en actividades de ecoturismo. Esto conlleva a que exista una mayor intervención de actores 
con intereses en desarrollo ecoturístico, así como en la conservación de las aéreas protegidas por la presión que puede existir en estas áreas.

En la zona maya hay aproximadamente once cooperativas turísticas que, por lo general, poseen un carácter familiar y social, las cuales cumplen con una función de diversificación del trabajo generado por el apoyo de las organizaciones nacionales e internacionales (Güemes, 2008), entre éstas destacan dos cooperativas en la comunidad de Muyil administradas por una sola familia que posee un sistema ejidal y que cuenta con 190 habitantes de los cuales tan solo 18 personas $(9.4 \%)$ trabajan en ecoturismo. En Punta Laguna, otra comunidad con el mismo régimen de tenencia de la tierra, existe una cooperativa turística donde participan 23 personas (17.6\%) de un total de 130 habitantes. Por otro lado, en Punta Allen donde el sistema de tenencia de la tierra es diferente: propiedad privada y tierras federales, existen cuatro cooperativas turísticas en las cuales participan en ecoturismo 68 personas $(10.7 \%)$ del total de la población que es de 630 habitantes. Los porcentajes de las personas que trabajan con ecoturismo son similares, en proporción, al número total de habitantes, por lo que las diferencias pueden estar asociadas a la forma en que éstas gestionan y ejecutan sus proyectos. La situación encontrada en las comunidades Punta Laguna y Muyil contrasta con los objetivos de las agencias internacionales y el discurso político de las dependencias gubernamentales, ya que los beneficios del ecoturismo se focalizan principalmente en las cooperativas por medio de las ONG, sin que llegue el beneficio a la mayoría de los pobladores por el hecho de no participar en organizaciones jurídicamente establecidas. Esto genera resultados diferenciales al interior de las cooperativas y de las comunidades, dejando como beneficiario real de esta actividad a las operadoras turísticas y a las agencias de viajes, porque actúan como intermediarios directos entre el turismo nacional y extranjero con las cooperativas que son las que ofrecen el atractivo turístico. Los factores que impulsan el desarrollo del ecoturismo son las estrategias que instrumentan las dependencias gubernamentales y las ONG a favor de esta actividad y, por parte de las organizaciones comunitarias, la necesidad de incursionar en nuevas actividades para mejorar su nivel de vida. Estos resultados coinciden con lo encontrado por Güemes (2008) quien deduce que los proyectos implementados en la región se han mantenido gracias a los subsidios que reciben de las organizaciones gubernamentales y las ONG. Al contrario de lo que plantea el principio del ecoturismo en términos de educar a todos los actores acerca de su papel en la conservación; este estudio comprobó que los programas de apoyo se centran en los rubros de construcción de infraestructura, adquisición de equipamientos y capacitación. En lo correspondiente a la capacitación, ésta se focaliza en incrementar la calidad del servicio al turista 
más que en aspectos de conservación y fortalecimiento integral de las capacidades.

Las principales limitantes manifestadas por los socios de las cooperativas son la falta de cultura ambiental y educación básica para poder desarrollar sus actividades, establecer vínculos con las operadoras turísticas para evitar que estos intermediarios se aprovechen de sus servicios, y fomentar la conservación a nivel local.

Con respecto a la vinculación entre los actores, a pesar de que existe un número considerable de posibles relaciones (197), el bajo porcentaje en la densidad muestra que las relaciones efectivamente existentes son pocas y esto se confirma con el indicador de centralidad, el cual es el resultado de que los actores se vinculen directamente con otros dependiendo de sus objetivos, sus temas de interés común y sus áreas de acción.

Un factor que posiblemente limitó el hecho de conocer a otros actores que los informantes pudieron omitir por desconocimiento o por no considerarlos vinculados a ellos, a pesar de que participan activamente en el ecoturismo, fue el tipo de metodología empleada (bola de nieve), ya que esta técnica da prioridad a obtener contactos a partir de una entrevista hasta formar una red de informantes clave. Estos posibles actores que no se mencionaron utilizando la metodología referida son los organismos internacionales (BM, BID y FMI), que controlan las políticas internas de los países y que tienen una fuerte influencia en las legislaciones locales imponiendo principios rectores totalmente intervencionistas para colocar a los países en el camino del desarrollo sustentable.

\section{Conclusiones}

En esta investigación hemos presentado los fundamentos teóricos de las políticas turísticas mexicanas y los efectos de éstas en la zona maya de Quintana Roo. Las políticas turísticas se han movido dentro del contexto macroeconómico y, a pesar de que han cambiado de modelo, siguen atendiendo a objetivos impuestos por los organismos internacionales de desarrollo como el BM, el FMI y el BID. Los Centros Integralmente Planificados (CIP) implementados en los años sesenta, continúa, siendo un instrumento de crecimiento económico para el estado y el país, sin embargo, sus efectos se han reflejado en la actual estructura socioeconómica y ambiental de las localidades cercanas al corredor turístico CancúnTulum como la sobreexplotación de los recursos naturales, los procesos de migración no controlada, la formación de asentamientos irregulares, la marginación de la población autóctona, la pérdida de la autonomía política, económica y cultural, delincuencia y prostitución. 
Las inversiones por parte de las dependencias gubernamentales y las ONG cumplen un papel importante para la formación de grupos y permanencia de los proyectos ecoturísticos. Asimismo, las instituciones académicas como la Universidad Nacional Autónoma de México, UnAM, El Colegio de la Frontera Sur, Ecosur, y el Centro de Investigaciones y Estudios Superiores en Antropología Social, CIESAS apoyan los proyectos ecoturísticos, aunque de manera aislada, con cursos de capacitación e investigación de interés para los grupos organizados. Sin embargo, los apoyos a estos proyectos, en lugar de fortalecer los procesos de gestión y toma de decisiones por parte de los involucrados, contribuyen a una dependencia de los subsidios para permanecer vigentes.

El tipo de relación y estrategias focalizadas que realizan los actores no son suficientes para que el ecoturismo tenga un impacto positivo en las comunidades, sobre todo, las localidades indígenas persistiendo así, los altos índices de marginación y pobreza. El éxito del ecoturismo depende de los intereses y los tipos de vínculos que establecen los actores para alcanzar los objetivos de conservación y bienestar de las comunidades.

\section{Bibliografía}

Ashley, Caroline (2000), The impacts of tourism on rural livelihoods: Namibia's experience, Overseas Development Institute, Chameleon Press, London.

Boo, Elizabeth (1990), Ecoturismo: potenciales y escollos, World Wildlife Fund and Conservation Foundation, Washington.

Borgatti, Stephen Peter (2002), NetDraw: Graph visualization software, ma: Analytic Technologies, Harvard.

Brown, Denise Fay (1999), "Mayas and tourists in the maya world", Human Organization, 58 (3), Society for Applied Anthropology, Oklahoma, pp. 295-304.

Castillo, Marcelino y Elva Esther Vargas (2007), "Breve recuento de la modernización de la política turística mexicana", Teoría y Praxis, 3 (3), Universidad de Quintana Roo, Cozumel, pp. 9-34, http://www.teoriaypraxis.ugroo.mx/, consultado el 4 de septiembre de 2010 .

Carballo, Arturo (2002), "Participación comunitaria en el ecoturismo sustentable en el Caribe Mexicano", Ciencia y desarrollo, XXVII 
(163), Consejo Nacional de Ciencia y Tecnología (Conacyt), México, pp. 37-47.

Ceballos-Lascuráin, Héctor (1998), Ecoturismo, naturaleza y desarrollo sustentable, editorial Diana, México.

Comisión Mundial para el medio ambiente y el desarrollo (Comisión Brundtland) (1987), Nuestro futuro común, Alianza Editorial, Madrid.

Conanp (Comisión Nacional de Áreas Naturales Protegidas) (2007), "Programa de Conservación y Manejo: Reserva de la Biosfera Sian ka'an, Reserva de la Biosfera Arrecifes de Sian ka'an y Área de Protección de Flora y Fauna Uaymil”, Conanp, México.

Conanp (Comisión Nacional de Áreas Naturales Protegidas) (2006), "Programa de Conservación y Manejo Área de Protección de Flora y Fauna Otoch Ma'Ax Yetel Kooh”, Conanp, México.

Daltabuit, Magali, Héctor Cisneros, Luz María Vázquez y Enrique Santillán (2000), Ecoturismo y desarrollo sustentable. Impacto en comunidades rurales de la selva maya, UNAM-CRIM, México.

Dachary, César (1992), "Quintana Roo: Los retos del fin de siglo ¿Hacia un desarrollo desigual?”, en César Darchary y Stella Arnaiz (eds.), Quintana Roo: los retos del fin del siglo, Universidad del Estado de Quintana Roo, México, pp. 9-29.

Drumm, Andy and Allan Moore (2002), Desarrollo del ecoturismo: Un manual para los profesionales de la conservación, The Nature Conservancy, Arlington Virginia.

Estrada-Lugo, Erín (2005), "Grupo doméstico y usos del parentesco entre los mayas macehuales del centro de Quintana Roo. El caso del ejido Xhazil Sur y Anexos", tesis doctoral, Universidad Iberoamericana, México.

Güemes-Ricalde, Francisco (2008), "Entorno globalizado y eficiencia económica de pequeñas empresas de turismo de naturaleza en el estado de Quintana Roo, México", en Francisco Güemes Ricalde (coord.), Contexto de planeación y mercados turísticos en el estado 
de Quintana Roo. Universidad de Quintana Roo, Chetumal, pp. 41-59.

INEGI (Instituto Nacional de Estadística, Geografía e Informática) (1996), "Conteo de Población y Vivienda 1995, resultados preliminares", INEGI, México.

INEGI (Instituto Nacional de Estadística, Geografía e Informática) (2007), "Hombres y mujeres en México", Aguascalientes, México.

Monfort, Vicente Mir (2000), "La política turística: una aproximación", Cuadernos de turismo, 6, Universidad de Murcia, España, pp. 7-27.

Pérez, Graciela y Carrascal Eurosia (2000) “El desarrollo turístico en Cancún, Quintana Roo y sus consecuencias sobre la cubierta vegetal", Investigaciones Geográficas, Boletín del Instituto de Geografía, núm. 43, unAM, pp. 145-166.

PNUD (Programa de las Naciones Unidas para el Desarrollo) (2006), Evaluación del Programa compaCT Sian Ka'an, Centro de Investigación y de Estudios Avanzados del ipN, Mérida, México.

Román, Patricia (2007), "La participación familiar en micronegocios en la ciudad de México", ponencia presentada en la 5a reunión: Escenarios de la diversidad: pasado y presente, Universidad Iberoamericana, 26-28 de septiembre, Distrito Federal.

Rome, Abigail (1999), "Monitoreo de los impactos turísticos: Un examen de metodologías y recomendaciones para el desarrollo de programas de monitoreo en América Latina”, Serie Informes Técnico Ecoturismo, 1, The Nature Conservancy, Agencia de los Estados Unidos para el Desarrollo Internacional, USAID, Washington, DC.

Secaira, Fernando y Gerardo García (2006), Una visión para el futuro: Cartografía de las selvas maya, zoque y olmeca, TNC, CI, ECOSUR, FDN, PFB, PPY, wCS, San José de Costa Rica.

Sectur (Secretaría de Turismo) (2002), "Estadísticas del sector turismo", Gobierno del estado de Quintana Roo, México. 
Sectur (Secretaría de Turismo) (2007), Elementos para evaluar el impacto económico, social y ambiental del turismo de naturaleza en México, Secretaría de Turismo, México.

The Ecotourism Society (1993), Ecotourism guidelines for nature tour operations, The Ecotourism Society, Bennington, Vermont.

Velázquez, Alejandro y Norman Aguilar (2005), Manual introductorio al análisis de redes sociales. Centro de Capacitación y Evaluación para el Desarrollo Rural s.c., Universidad Autónoma del Estado de México, México.

Recibido: 4 de octubre de 2010. Reenviado: 29 de julio de 2011. Aceptado: 5 de octubre de 2011.

Maria Raimunda Araújo-Santana. Es doctora en ciencias en ecología y desarrollo sustentable por El Colegio de la Frontera Sur, San Cristóbal de las Casas, Chiapas. Es profesora-investigadora del Instituto de Ciencias Agropecuarias (ICAP), de la Universidad Autónoma del Estado de Hidalgo (UAEH). Sus líneas de investigación actuales son: Desarrollo socioeconómico de comunidades rurales, aporte económico del turismo y productos no maderables. Sus publicaciones más recientes son: "Perceptions of the degradation and restoration of forest ecosystems in Southeastern Hidalgo State, Mexico", en F. Montagnini y C. Finney (eds), Restoring degraded landscapes with native species in Latin America, Nova Science Publishers, New York, pp. 159-171 (2011); en coautoría: "Aporte económico del ecoturismo a las estrategias de vida de grupos domésticos de la península de Yucatán, México", Pasos. Revista de Turismo y Patrimonio Cultural, 11 (1), Universidad de la Laguna, Tenerife, pp. 185-204 (2013); "Participatory approaches to ecosystem restoration in Hidalgo, México", Bois et forests des tropiques, Cirad, France, 295 (1), pp. 5-20 (2008).

Manuel Roberto Parra-Vázquez. Es doctor en economía por la Universidad Nacional Autónoma de México. Actualmente está adscrito a El Colegio de la Frontera Sur, Unidad de San Cristóbal de las Casas, Chiapas. Su línea de investigación actual es: Sistemas Socioambientales. Entre sus publicaciones más recientes, destacan, en coautoría: "Aporte económico del ecoturismo a las estrategias de vida de grupos domésticos de la península de Yucatán, México", Pasos, Revista de Turismo y Patrimonio Cultural, 11 (1), Universidad de la Laguna, pp. 185-204 (2013); "Fores- 
tería comunitaria y desarrollo de instituciones locales: El caso de la comunidad agraria Teopisca", Economía Sociedad y Territorio, IX (30), Colegio Mexiquense, Zinacantepec, 349-395 (2009); "Estrategias de vida, sistemas agrícolas e innovación en el municipio de Oxchuc, Chiapas. Revista de Geografía Agricola, 42, p. 83-106 (2009); "Impacto de las estrategias de ingresos sobre la seguridad alimentaria en comunidades rurales mayas del norte de Campeche", Archivos Latinoamericanos de $\mathrm{Nu}$ trición, 60 (1), Caracas, pp. 48-55 (2010).

Ernesto Benito Salvatierra-Izaba. Es doctor en estudios de desarrollo rural por el Colegio de Posgraduados, con especialidad en políticas de población. Actualmente está adscrito a El Colegio de la Frontera Sur, en el área de Sociedad, Cultura y Salud. Su línea de investigación es Sociedad, cultura y salud. Sus publicaciones más recientes, en coautoría, son: "Aporte económico del ecoturismo a las estrategias de vida de grupos domésticos de la península de Yucatán, México", Pasos. Revista de Turismo y Patrimonio Cultural, 11 (1), Universidad de la Laguna, pp. 185-204 (2013); "Mortalidad infantil y migración en Chiapas", Población y salud en $\mathrm{Me-}$ soamérica, 8 (1), pp. 1-19 (2010); "Envejecimiento, calidad de vida y mortalidad temprana en hombres diabéticos. Una aproximación desde la perspectiva de género", Papeles de Población, 16 (64), Universidad Autónoma del Estado de México, pp. 67-92 (2010); "Indicadores técnicos y económicos de los sistemas silvopastoriles del municipio de Tecpatán, Chiapas", en Aguirre et al. (comps), Bienestar animal en sistemas silvopastoriles, V Reunión Nacional sobre Sistemas Agro y Silvopastoriles, Universidad Autónoma de Nayarit y Consejo de Ciencia y Tecnología del Estado de Nayarit, Nayarit, pp. 29-36, (2010).

Ana Minerva Arce-Ibarra. Es doctora en estudios interdisciplinarios por la Universidad de Dalhousie, Canadá. Actualmente está adscrita al área de Sistemas de Producción Alternativos del Colegio de la Frontera Sur, Unidad Chetumal, Quintana Roo. Sus temas de investigación son los recursos naturales en general y pesquería de pequeña escala utilizando enfoques disciplinarios e interdisciplinarios. Su línea de investigación actual es: Pesquerías artesanales. Entre sus publicaciones destacan: "Aporte económico del ecoturismo a las estrategias de vida de grupos domésticos de la península de Yucatán, México", Pasos. Revista de Turismo y Patrimonio Cultural, 11 (1), Universidad de la Laguna, pp. 185-204 (2013); "Pesquerías: sector social, recurso base y manejo", en Espinoza-Ávalos et al. (eds.), El sistema ecológico de la bahía de Chetumal / Corozal: costa occidental del Mar Caribe, El Colegio de la Frontera Sur, Chetumal, Quintana Roo, 184-195 (2009); "El sector forestal en Chiapas: un análisis 
desde la perspectiva de la economía ecológica", Nova Scientia, Revista de Investigación de la Universidad de la Salle Bajío, 2 (1), Universidad de La Salle Bajío, León, pp. 37-50 (2009); "Estudios interdisciplinarios de los mayas y sus recursos naturales en Quintana Roo”, en Bello-Baltazar et al. (eds.), Innovación socioambiental y desarrollo en la frontera sur de México, El Colegio de la Frontera Sur, México, pp. 64-67 (2010).

Florencia Montagnini. Es doctora en ecología por la Universidad de Georgia, Athens, Georgia Estados Unidos. Actualmente está adscrita a la Escuela Forestal y de Estudios del Medio Ambiente de la Universidad de Yale, Connecticut, usa. Funge como directora del Programa de Silvicultura Tropical en la misma universidad. Su línea de investigación se centra en plantaciones y sistemas agroforestales con énfasis en América Latina. Sus publicaciones más recientes son: "Can tree plantations serve as catalysts of secondary forest succession?, Journal of Sustainable Forestry, Yale University, New Haven (2008); "Participatory approaches to ecosystem restoration in Hidalgo, México", Bois et Forests des Tropiques, Cirad, France, 295 (1), pp. 5-20 (2008) y en coautoría: "Perceptions of the degradation and restoration of forest ecosystems in Southeastern Hidalgo State, Mexico", en F. Montagnini y C. Finney (eds), Restoring degraded landscapes with native species in Latin America, Nova Science Publishers, New York, (2011). 